\title{
PENGARUH KEPEMILIKAN NPWP, PEMERIKSAAN, PENAGIHAN, KESADARAN WP TERHADAP PENERIMAAN PAJAK BADAN DI KPP PRATAMA GIANYAR
}

\author{
Tjok Gde Agung Anggadhika W.P.P ${ }^{1}$ \\ I Ketut Jati \\ ${ }^{1}$ Fakultas Ekonomi dan Bisnis Universitas Udayana, Denpasar, Bali \\ e-mail: anggadhika1@gmail.com \\ ${ }^{2}$ Fakultas Ekonomi dan Bisnis Universitas Udayana, Denpasar, Bali
}

\begin{abstract}
ABSTRAK
Tujuan penelitian ini adalah untuk menemukan pengaruh kepemilikan NPWP, pemeriksaan, penagihan, dan kesadaran WP Terhadap Penerimaan Pajak Badan Di KPP Pratama Gianyar. Penelitian ini menggunakan teknik analisis regresi linear berganda. Aplikasi dipergunakan terlebih dahulu untuk mendapatkan tingkat Normalitas dan Heterokedastisitas sebelum dilakukan analisis. Hasil analisis secara statistik, menunjukkan pengaruh kepemilikan NPWP, pemeriksaan, penagihan, dan kesadaran wajib pajak dengan tingkat signifikansi t masing-masing sebesar 0,039; 0,004; 0,046; 0,000. Ini bermakna setiap variabel memiliki pengaruh positif dan signifikan pada peneriman pajak badan. Direktorat Jendral Pajak (DJP) sebagai badan yang bertugas melaksanakan tugas perpajakan khususnya KPP Pratama Gianyar yang melaksanakan tugasnya dengan baik agar terus semakin meningkatkan kepemilikan npwp dengan melakukan penyuluhan ke wajib pajak yang belum ber-npwp serta penyuluhan untuk meningkatkan kesadaran wajib pajak. Sehingga dapat meningkatkan penerimaan pajak terutama di KPP Pratama Gianyar
\end{abstract}

Kata kunci:NPWP, Pemeriksaan, Penagihan,

\begin{abstract}
Purpose of this research is to find the effect of NPWP ownership, audit, collection and corporate taxpayer's awareness to tax revenue in Gianyar KPP Pratama. Technique analysis used in this is multiple linear regressions. Before analysis process, Normality and Heterocedasticity Test were carried out using the SPSS program. The results of statistical analysis, showing the effect of NPWP ownership, audit, collection, and corporate taxpayers awareness with a significance level of $\mathrm{t}$ each of $0.039 ; 0,004 ; 0.046 ; 0,000$. This means that the taxpayer's awareness bring positive and significant effect on tax revenue. For DJP which assigned to carry out taxation tasks, especially KPP Gianyar Pratama which has carried out its duties well so that in the future it will increase ownership of NPWP by conducting counseling taxpayers who have not registered and counseling to increase corporate taxpayer awareness. So that it can increase tax revenue, especially in KPP Pratama Gianyar

Keywords: NPWP, Inspection, Billing,
\end{abstract}


Tjok Gde Agung Anggadhika W.P.P, dan I Ketut Jati. Pengaruh Kepemilikan NPWP...

\section{PENDAHULUAN}

Pembangunan di Indonesia saat ini sedang dilakukan secara besar-besaran, dimana tujuan pembangunan itu adalah untuk demi kesejahteraan rakyat secara spiritual dan material. Agar dapat membiayai pembangunan itu maka pemerintah memerlukan biaya yang berasal dari pendapatan negara. Menurut Anggaran Pendapatan Belanja Negara (APBN) 5 tahun terakhir (APBN 2012-2016) sumber pendapatan terbanyak berasal dari pajak walaupun terdapat sektor lain seperti bantuan luar negeri, serta minyak dan gas bumi. Pajak sebagai sumber penerimaan negara terbesar maka bisa dijadikan solusi untuk pembiayaan pembangunan negara, karena penerimaan langsung bisa digunakan untuk membiayai berbagai keperluan negara (Listyaningtyas, 2012), seperti terlihat dalam tabel dibawah

Tabel 1.

Realisasi Pendapatan Negara Periode Tahun 2012-2016 (dalam miliar rupiah)

\begin{tabular}{lrrrrr}
\hline \multicolumn{1}{c}{ Sumber } & 2012 & 2013 & 2014 & 2015 & 2016 \\
\hline 1.Pendapatan Pajak & 980518 & 1077306 & 1146865 & 1240418 & 1539166 \\
a.Pajak dari Dalam Negeri & 930,862 & $1,029,850$ & $1,103,218$ & $1,205,479$ & $1,503,295$ \\
1) PPh & 465,070 & 506,443 & 546,181 & 602,308 & 855,843 \\
2) PPN & 337,585 & 384,714 & 409,182 & 423,711 & 474,235 \\
3) PBB & 28,969 & 25,305 & 23,476 & 29,250 & 17,711 \\
4) BPHB & - & - & - & - & - \\
5) Cukai & 95,028 & 108,452 & 118,086 & 144,641 & 148,091 \\
6) Pajak Lain-lain & 4,211 & 4,937 & 6,293 & 5,568 & 7,415 \\
b.Pajak dari Perdagangan & & & & & \\
International & 49,656 & 47,457 & 43,648 & 34,940 & 35,872 \\
1) Bea Masuk & & & & & \\
2) Pajak Ekspor & 28,418 & 31,621 & 32,319 & 31,213 & 33,372 \\
2. Pendapatan Bukan Pajak & 21,238 & 15,835 & 11,329 & 3,727 & 2,500 \\
a. Sumber Daya Alam & 351,805 & 354,752 & 398,591 & 255,628 & 245,084 \\
b. Laba BUMN & 225,844 & 226,406 & 240,848 & 100,972 & 90,524 \\
c. PNPB Lain-lain & 30,798 & 34,026 & 40,314 & 37,644 & 34,164 \\
d. BLU & 73,459 & 69,672 & 87,747 & 81,697 & 84,124 \\
& 21,704 & 24,648 & 29,681 & 35,315 & 36,271
\end{tabular}




\begin{tabular}{lrrrrr} 
3. Hibah & 5,787 & 6,833 & 5,035 & 11,973 & 1,975 \\
\hline Jumlah/Total & $1,338,110$ & $1,438,891$ & $1,550,491$ & $1,508,020$ & $1,786,225$ \\
\hline
\end{tabular}

Sumber: BPS RI dan Departemen Keuangan, periode tahun 2012-2016

Direktorat Jendral Pajak (DJP) berusaha agar Wajib Pajak (WP) tanpa paksa membayar pajaknya. Ini dikarenakan semakin banyaknya Wajib Pajak mendapatkan penghasilan maka penerimaan negara melalui pajak akan bertambah. timbulnya kemungkinan kerugian karena pemberlakukan aturan penghapusan pajak pun bisa diatasi. Demi menahan potensi itu, DJP telah memprediksi serta diimbangi serta penerimaan pajak yang bersumber oleh tumbuhnya kepemilikan NPWP. Penadapatan pajak bisa didapatkan berdasarkan Surat Ketetapan Pajak yang dilaporkan oleh WP ber NPWP

Tabel 2.

Jumlah Wajib Pajak Terdaftar di KPP Pratama Gianyar Tahun 2012-2016

\begin{tabular}{ccc}
\hline Periode Tahun & Wajib Pajak Terdaftar & Peningkatan (\%) \\
\hline 2012 & 116.905 & - \\
2013 & 126.305 & $8,04 \%$ \\
2014 & 137.999 & $9,26 \%$ \\
2015 & 150.346 & $8,94 \%$ \\
2016 & 161.754 & $7,59 \%$ \\
\hline
\end{tabular}

Sumber: KPP Pratama Gianyar, 2017

Pada Tabel 2 terlihat sampai akhir tahun 2016 KPP Pratama Gianyar tercatat memiliki 161.754 WP. Tahun 2012 hingga tahun 2016 jumlah WP yang terdaftar di KPP Pratama Gianyar selalu terjadi Peningkatan. Peningkatan paling besar berlangsung di tahun 2014, yaitu sejumlah 9,26\% dan pertumbuhan terkecil pada tahun 2016 yaitu 7,59\%.

Peningkatan tertinggi realisasi pertumbuhan penerimaan pajak pada KPP Pratama Gianyar terjadpada tahun 2015, yaitu sebesar 39,06 persen. Periode 2014, pertumbuhan penerimaan 
Tjok Gde Agung Anggadhika W.P.P, dan I Ketut Jati. Pengaruh Kepemilikan NPWP...

pajak mengalami penurunan sebesar 3,02 persen. Namun pada tahun berikutnya mengalami peningkatan yang signifikan. Peningkatan dari penerimaan inipun tetap terjadi pada tahun 2016 walaupun tingkat pertumbuhan tidak sebesar tahun 2015. Penerimaan dan pertumbuhan fluktuatif pajak, seperti terlihat dalam tabel berikut :

Tabel 3.

Penerimaan Fluktuatif Pajak pada Kantor Pajak Pratama Gianyar Periode tahun 2012-2016

\begin{tabular}{ccc}
\hline Tahun & Jumlah Penerimaan & Pertumbuhan (\%) \\
\hline 2012 & 316.700 .000 & - \\
2013 & 367.200 .000 & 15,94 \\
2014 & 356.100 .000 & $-3,02$ \\
2015 & 495.200 .000 & 39,06 \\
2016 & 637.300 .000 & 28,70
\end{tabular}

Sumber: Kantor Pelayanan Pajak Pratama Gianyar, 2017

Pemeriksaan pajak dilakukan selaku bentuk pengawasan dan pembinaan bagi wajib pajak yang dilakukan oleh Direkturat Jenderal Pajak (DJP) agar pemungutan pajak dilaksanakan sesuai dengan perundangan perpajakan. Selain itu pemeriksaan pajak dilakukan agar WP nakal mendapat efek jera hingga tidak mengulang perbuatannya dimasa depan. Melalui pemeriksaan 
itulah mengakibatkan adanya pengawasan dan pembinaan yang terus-menerus terhadap wajib pajak

Selain pemeriksaan pajak terdapat kebijakan yang dilaksanakan sebagai cara agar memaksimalkan penerimaan pajak yakni melaksanakan penagihan pajak semakin giat pada tiap wajib pajak yang memiliki hutang pajak. Penagihan pajak dilaksanakan dikarenakan banyak WP yang tidak melaksanakan kewajiban pajaknya hingga diharuskan dilakukannya penagihan sehingga memiliki kepastian hukum yang bersifat mengikat dan memaksa

Memaksimalkan penerimaan pajak dengan system self-assessment, bersama dengan meningkatkan WP aktif, Pemeriksaan dan penagihan, DJP juga berusaha agar WP lebih sadar bahwa kewajiban bayar pajak sangat vital demi terlaksananya pembangunan nasional. Demi menumbuhkan kesadaran perpajakan ini, pemerintah menjalankan sejumlah tindakan sosialisasi perpajakan yang bermaksud memberikan pengertian untuk masyarakat berkaitan perpajakan di Indonesia

Menurut Undang-Undang Nomor 28 Tahun 2007 tentang Ketentuan Umum dan Tata Cara Perpajakan (UU KUP), dalam Pasal 1mengatakan "Pajak adalah kontribusi wajib pada negara yang terutang oleh orang pribadi atau badan yang bersifat memaksa berdasarkan undangundang, dengan tidak mendapatkan imbalan secara langsung dan digunakan untuk keperluan negara bagi sebesar-besarnya kemakmuran rakyat". Pajak merupakan iuran yang bersumber dari rakyat yang dibayarkan ke dalam kas negara berdasarkan perundang-undangan yang dapat dipaksakan dengan tiada mendapatkan timbal balik dipergunakan untuk membiayai pengeluaran negara. Sedangkan NPWP ialah nomor register yang diberikan pada WP untuk 
sarana administrasi pajak dan diperuntukan sebagai identitas WP untuk menyelesaikan hak dan kewajiban pajaknya (Mardiasmo, 2011).

WP yang sudah melaksanakan syarat subjektif dan objektif sesuai aturan perundangan perpajakan melalui self assessment, harus mendaftarkan diri di KPP Pratama agar tercatat sebagai WP dan sekaligus guna memperoleh NPWP. Syarat objektif ialah syarat untuk wajib pajak yang memperoleh atau mendapatkan penghasilan yang diharuskan dipotong/dipungut sesuai dengan Aturan Perundangan Pajak Penghasilan Tahun 1984 serta segala perubahannya (Diana \& Setiawati, 2009).

UU KUP mengatakan pemeriksaan pajak adalah tindakan mengumpulkan dan/atau menganalisa data serta keterangan, dan/atau bukti yang dilakukan secara profesional dan objektif. Hal-hal tersebut dilakukan untuk menguji kepatuhan pemenuhan kewajiban perpajakan. Menurut Pardiat, pemeriksaan pajak dilakukan dengan meneliti bukti-bukti berupa buku-buku, dokumendokumen maupun catatan-catatan dengan cara objektif serta profesional berlandaskan standar pemeriksaan dari Direktorat Jendral Pajak (DJP), untuk menilai kepatuhan kewajiban perpajakan WP dan/atau untuk hal-hal lainnya yang terdapatdi dalam ketentuan perundangundangan perpajakan (Pardiat, 2008).

Menurut Undang-undang Nomor 19 Tahun 2000 tentang Penagihan Pajak dengan Surat Paksa (UU PPSP), dalam Pasal 1 butir 9, pengertian penagihan pajak yaitu serangkaian perbuatan penanggung pajak untuk melunasi hutang pajak beserta biaya penagihan pajak dengan cara menegur dan/atau memperingatkan dan/atau melaksanakan penagihan secara seketika dan/atau sekaligus menyampaikan surat paksa dan/atau melakukan pencegahan dan/atau penyitaan dan/atau penyanderaan dan/atau menjual barang yang disita dari WP (Rahayu, 2014). 
Menurut KBBI kesadaran adalah keinsafan; keadaan mengerti; kesadaran nilai-nilai dalam diri manusia mengenai hukum; pengetahuan seseorang bahwa suatu terdapat aturan hukum bagi perilaku tertentu. Jadi bisa diartikan kesadaran WP adalah situasi dimana WP mengetahui dan mengerti untuk melakukan ketentuan perpajakan secara benar dan sukarela. WP harus mengikuti aturan itu dengan baik dan ikhlas. Maka, kesadaran WP merupakan keadaan dimana WP tahu, mengakui, menghargai serta mentaati peraturan pajak dan mempunyai keinginan serta bersungguh-sungguh guna melaksanakan kewajiban pajaknya.

WP disebut mempunyai kesadaran bila (Manik, 2009), tahu adanya perundangan serta aturan pajak, tahu guna pajak sebagai pembiayaan negara, paham maka kewajiban pajak dilakukan berpatut dengan aturan yang berlangsung, paham fungsi pajak sebagai pembiayaan negara, hitung, bayar, lapor pajak secara tanpa paksaan, dan dengan benar

Berdasarkan penelitian terdahulu yang dilakukan (Sutrisno, Arifati, \& Andini, 2016), terkait kewajiban kepemilikian NPWP maka makin banyak WP yang mempunyai NPWP maka menambah penerimaan pajak. NPWP ialah sarana administrasi perpajakan yang digunakan untuk identitas WP. Menurut penelitian yang dilakukan oleh (Saragih, 2017) didapatkan nilai korelasi antara kepemilikan NPWP terhadap Penerimaan pajak yaitu sejumlah 0,792 yang tergolong dalam kategori hubungan yang kuat, berarti setiap kenaikan kepemilikan NPWP akan meningkatkan potensi penerimaan pajak. Kondisi ini menunjukkan hasil yang didapatkan peneliti telah sesuai dengan teori yang dikatakan oleh Bambang Brodjonegoro (2016:79), yang menyatakan bahwa Negara dapat mengoptimalisasi penerimaan pajak dengan baik yaitu dengan lebih menekankan kepada masyarakat agar memiliki NPWP dan penekanan WP 
Sedang berdasarkan (Chatama, 2013), kepemilikan npwp tidak mempengaruhi secara parsial pada penerimaan pajak, diukur berdasarkan nilai t-hitung lebih rendah dibanding t-hitung. Dan tidak mempengaruhi secara simultan pada penerimaan pajak, didapat berdasarkan nilai signifikan uji statistik f yang >0,05 (0,0527>0.05).

$\mathrm{H}_{1}$ : Kewajiban kepemilikan Nomor Pokok Wajib Pajak (NPWP) berpengaruh positif pada penerimaan pajak di KPP Pratama Gianyar

Pada penelitian Listyaningtyas, daya guna dari bidang penuntasan periode tahun 2009-2010 masuk didalam parameter efektif dengan persentase 100\%, sedang pada 2011 lumayan efektif dengan persentase $85,71 \%$ yang ditaksir menurut pnagihan dan pembayaran bagi Surat Perintah Pemeriksaan Pajak (SP3). Efektivitas atas bidang penuntasan dari hasil pemeriksaan periode tahun 2009-2011 sugguh efektif dengan persentase 110,03\%, 104,35\%, dan 105,02\% yang didapatkan berdasarkan penagihan dan pembayaran ketetapan pemeriksaan. Data-data efektivitas dari bidang penuntasan dan efektivitas dari bidang penuntasan penerimaan atas hasil pemeriksaan semuanya benar- benar diselesaikan secara baik, serta realisasi juga melebihi target KPP (Listyaningtyas, 2012).

Sedangkan penelitian oleh Rahmawati dkk, pemeriksaan pajak tidak memengaruhi penerimaan pajak di KPP Surakarta, dikarenakan Hasil penelitian memperlihatkan variabel Pemeriksaan Pajak mempunyai t-hitung -0,410 dengan signifikansi 0,685 > 0,05 dan mempunyai nilai koefisien regresi negatif, yang berarti data yang dianalisa gagal memperlihatkan efek pemeriksaan pajak bagi penerimaan Pajak Penghasilan (PPh) (Rahmawati, Santoso, \& Hamidi, 2014).

$\mathrm{H}_{2}$ : Pemeriksaan pajak berpengaruh positif pada penerimaan pajak di KPP Pratama Gianyar 
Menurut penelitian Mahendra tentang penagihan pajak terhadap penerimaan pajak, pada variabel penagihan pajak, koefisien regresinya bersifat positif sebesar $(0,470)$ dengan nilai signifikansi. t sebesar $0,004<0,05$. Hal ini berarti variabel penagihan pajak mempunyai refek positif terhadap penerimaan PPh badan. Memperlihatkan kenaikan penagihan pajak akan menyebabkan naiknya penerimaan pajak penghasilan badan (Mahendra, 2014). hasil ini didukung oleh penelitian Syahab yang mendapatkan hasil penagihan pajak mempunyai pengaruh positif dan signifikan terhadap PPh badan (Syahab, 2008). Menurut (Nana,2012), penagihan pajak dengan surat teguran dan/atau surat paksa mengalami kenaikan dari tahun 2010-2011 baik dari jumlahnya dan juga nilai pajak terhutang yang mendapatkan surat teguran dan/atau surat paksa. Demikian juga pembayaran terhadap tunggakan pajak dengan surat teguran dan/atau surat paksa tejadi kenaikan baik dari jumlah surat yang dibayarkan terhadap tunggakan pajak berdasarkan surat teguran dan/atau surat paksa dan juga nilai pembayaran pajak terhutang dengan surat paksa (Putra Mahendra \& Sukartha, 2014).

Sedangkan penelitian oleh (Fahrul, 2016), menemukan bahwa penagihan pajak tidak memengaruhi penerimaan pajak, disebabkan oleh dengan nilai koefisien regresi negatif, yang berarti data yang dipakai gagal memperlihatkan pengaruh pemeriksaan pajak pada penerimaan Pajak Penghasilan

$\mathrm{H}_{3}$ : Penagihan pajak berpengaruh positif pada penerimaan pajak di KPP Pratama Gianyar Penelitian (Herryanto, 2013) mengenai kesadaran WP terhadap penerimaan pajak membuktikan bahwa variabel kesadaran WP dengan bersama-sama variabel lainnya memiliki pengaruh pada penerimaan PPh di KPP Pratama Sawahan Surabaya. Kemudian pengujian parsial pada variabel kesadaran wajib pajak mendapatkan pengaruhnya terhadap PPh pada KPP Pratama Sawahan 
Tjok Gde Agung Anggadhika W.P.P, dan I Ketut Jati. Pengaruh Kepemilikan NPWP...

Surabaya secara positif. Dan menurut (Hastuti, 2014) Subjek sadar secara konstektual dan etikal bagaimana menjadi wajib pajak. Kesadaran wajib pajak disini mengacu bahwa pajak adalah pendaptan utama negara dan setiap warga negara harus taat pada pajak serta wajib untuk menghitung, membayar dan melapor pajak secara mandiri. Subjek setuju bahwa edukasi pajak penting untuk dipelajari mulai di pendidikan tinggi karena warga negara tidak bisa lepas dari pajak. Sedangkan pada penelitian Darwin, mendapatkan kesadaran wajib pajak tidak mempunyai pengaruh terhadap penerimaan pajak, dengan ditemukan nilai signifikan sebesar 0,272> alpha 0,05. Hal tersebut mempunyai makna bahwa kesadaran WP tidak memengaruhi kinerja penerimaan pajak di Kota Padang (Darwin, Darwin, \& Putri, 2014).

$\mathrm{H}_{4}$ : Kesadaran wajib pajak berpengaruh positif pada penerimaan pajak di KPP Pratama Gianyar

\section{METODE PENELITIAN}

Jenis data yang dikumpulkan di penelitian pada masing masing variable $\mathrm{X} 1, \mathrm{X} 2, \mathrm{X} 3$, $\mathrm{X} 4$, dan Y adalah data semi kuantitatif (skala ordinal) yaitu berupa jawaban atas pertanyaan mengenai kewajiban kepemilikan Nomor Pokok Wajib Pajak (NPWP), pemeriksaan pajak, penagihan pajak, kesadaran wajib pajak (WP), dan penerimaan pajak. Penelitian ini dilakukan pada Kantor Pelayanan Pajak (KPP) Pratama Gianyar

Populasi pada penelitian ini ialah WP badan yang terdaftar di KPP Pratama wilayah Gianyar. Sampel dari penelitian dipilih berdasarkan teknik Nonprobability Sampling Design yaitu pemilihan sampel yang tidak memberikan peluang atau memberikan kesempatan yang sama bagi tiap unsur anggota populasi untuk dapat terpilih menjadi sampel (Sugiyono, 2009). Metode teknik nonprobability sampling terpakai yaitu convinience sampling. convinience sampling. hal 
tersebut mempunyai makna setiap unit sampel tertarik akan mudah dihubungi, tidak membuat susah, dan mudah untuk diukur dan kooperatif (Hamid, 2010) Metode di penelitian memakai angket untuk memperoleh informasi responden. Angket yang digunakan penulis ialah angket tertutup, berarti angket yang sudah disediakan jawabannya. Dalam mengerjakan penilaian berdasarkan jawaban dari angket yang diberikan ke responden, memakai skala likert, untuk mengukur sikap, pendapat, dan persepsi seseorang atau sekelompok orang tentang fenomena social

Analisa regresi linier berganda menggunakan aplikasi software SPSS. Analisa dipergunakan untuk mendapatkan hasil akan pengaruh kewajiban kepemilikan Nomor Pokok Wajib Pajak (NPWP) $\left(\mathrm{X}_{1}\right)$, pemeriksaan pajak $\left(\mathrm{X}_{2}\right)$, penagihan pajak $\left(\mathrm{X}_{3}\right)$, kesadaran wajib pajak $(\mathrm{WP})\left(\mathrm{X}_{4}\right)$ terhadap penerimaan pajak badan (Y), dengan persamaan regresi dari penelitian ini sebagai berikut:

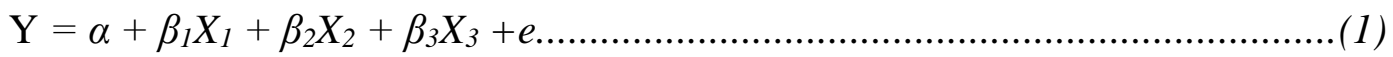

Keterangan:

$\mathrm{Y} \quad=$ penerimaan pajak

$\alpha=$ nilai konstanta

$\beta 1-\beta 4=$ koefisien regresi untuk $X_{1}, X_{2}, X_{3}, X_{4}$

$\mathrm{X}_{1} \quad=$ kewajiban kepemilikan Nomor Pokok Wajib Pajak (NPWP)

$\mathrm{X}_{2} \quad=$ pemeriksaan pajak

$\mathrm{X}_{3} \quad=$ penagihan pajak

$\mathrm{X}_{4} \quad=$ Kesadaran Wajib Pajak (WP)

$\mathrm{Y} \quad=$ standard error

\section{HASIL DAN PEMBAHASAN}

Data penelitian didapat berdasarkan jawaban kuisioner yang dibagikan pada responden dalam hal ini WP Badan yang sebanyak 100 orang di KPP Pratama Gianyar. Data karakteristik 
Tjok Gde Agung Anggadhika W.P.P, dan I Ketut Jati. Pengaruh Kepemilikan NPWP...

yang terdapat pada variabel penelitian adalah nilai minimun, maksimum, nilai mean, dan standar deviasi, yang terlihat pada Tabel 4:

Tabel 4.

Hasil Uji Statistik Berdasarkan Deskriptif

\begin{tabular}{cccccc}
\hline Variabel & $\mathrm{N}$ & Minimum & Maksimum & Mean & $\begin{array}{c}\text { Standar } \\
\text { Deviasi }\end{array}$ \\
\hline $\begin{array}{c}\text { Kepemilikan } \\
\text { NPWP }\left(\mathrm{X}_{1}\right)\end{array}$ & 100 & 2,2 & 5 & 3,96 & 3,441 \\
$\begin{array}{c}\text { Pemeriksaan } \\
\text { Pajak }\left(\mathrm{X}_{2}\right)\end{array}$ & 100 & 1,4 & 5 & 3,95 & 3,628 \\
$\begin{array}{c}\text { Penagihan Pajak } \\
\left(\mathrm{X}_{3}\right)\end{array}$ & 100 & 2 & 5 & 3,98 & 3,998 \\
$\begin{array}{c}\text { Kesadaran } \\
\text { Wajib Pajak } \\
\left(\mathrm{X}_{4}\right)\end{array}$ & 100 & 1,75 & 5 & 3,92 & 2,576 \\
$\begin{array}{c}\text { Penerimaan } \\
\text { Pajak (Y) }\end{array}$ & 100 & 2,83 & 4,83 & 4,096 & 2,727 \\
\hline
\end{tabular}

Sumber: Data Diolah, 2018

Dari tabel diatas yang diperlihatkan ialah nilai minimum, maksimum, mean serta standar deviasi. Nilai mean Kewajiban Kepemilikan NPWP sejumlah 3,96 dengan standar deviasi sejumlah 3,441. Nilai minimum Kewajiban Kepemilikan NPWP sejumlah 2,2 sementara nilai maksimum pada sampel yaitu sejumlah 5 .

Pemeriksaan Pajak mempunyai nilai mean sejumlah 3,95 dengan standar deviasi 3,628. Nilai minimum dari Pendapatan Asli Daerah adalah sejumlah 1,4 dan nilai maksimum sejumlah 5 
Pada table, mean Penagihan Pajak ialah 3,98 dengan standar deviasi 3,998. Penagihan Pajak mempunyai nilai minimum sejumlah 2 serta nilai maksimum sejumlah 5

Mean Kesadaran Wajib Pajak ialah sejumlah 3,92 dengan standar deviasi sebesar 2,576. Nilai minimum Kesadaran Wajib Pajak adalah sejumlah 1,75 Sedangkan maksimum dalam penelitian ini sejumlah 5

Penerimaan Pajak mempunyai nilai mean sebesar 4,096 dengan standar deviasi 2,727. Nilai minimum dari Pendapatan Asli Daerah ialah sejumlah 2,83 dan nilai maksimum sejumlah 5

Analisa regresi linier berganda dilakukan menggunakan aplikasi software SPSS. Analisa ini dipakai demi melihat pengaruh kewajiban kepemilikan Nomor Pokok Wajib pajak (NPWP) $\left(\mathrm{X}_{1}\right)$, pemeriksaan pajak $\left(\mathrm{X}_{2}\right)$, penagihan pajak $\left(\mathrm{X}_{3}\right)$, kesadaran wajib pajak (WP) $\left(\mathrm{X}_{4}\right)$ terhadap penerimaan pajak badan(Y)

Tabel 5.

Hasil Uji Analisis Regresi Linear Berganda

\begin{tabular}{|c|c|c|c|c|c|}
\hline \multirow[t]{2}{*}{ Variabel } & & Koefisien & \multirow{2}{*}{\multicolumn{2}{|c|}{ Koefisien Standar }} & \multirow[b]{2}{*}{ Sig. } \\
\hline & B & $\begin{array}{l}\text { Standar } \\
\text { eror }\end{array}$ & & $\mathrm{t}$ & \\
\hline (Constant) & 8.280 & 1.322 & & 6.261 & .000 \\
\hline $\begin{array}{c}\text { Kewajiban Kepemilikan } \\
\text { NPWP }\end{array}$ & .150 & .072 & .189 & 2.097 & .039 \\
\hline Pemeriksaan Pajak & .186 & .062 & .248 & 2.993 & .004 \\
\hline Penagihan Pajak & .135 & .067 & 197 & 2.022 & .046 \\
\hline Kesadaran Wajib Pajak & .410 & .083 & .387 & 4.947 & .000 \\
\hline
\end{tabular}

Sumber : Data Diolah, 2018

Melihat tabel diatas didapatkan model regresi berganda bagi penelitian ini, yaitu sebagai berikut:

$Y=8,280+0,150 X_{1}+0,186 X_{2}+0,135 X_{3}+0,410 X_{4}$ Persamaan regresi tersebut diatas dapat dijabarkan sebagai berikut: 
Tjok Gde Agung Anggadhika W.P.P, dan I Ketut Jati. Pengaruh Kepemilikan NPWP...

Didapatkan nilai konstansta sejumlah 8,280 bermakna bila tanpa adanya variabel kewajiban kepemilikan Nomor Pokok Wajib pajak (NPWP), Pemeriksaan Pajak, Penagihan Pajak, Kesadaran Wajib Pajak (WP), penerimaan pajak badan (Y) tetap meningkat sebesar 8,280. Dikarenakan adanya mekanisme yang memaksa pajak tetap dibayar, tanpa adanya variablevariabel terkait.

$\beta_{1}=0,150$; bermakna bila variabel kewajiban kepemilikan NPWP $\left(\mathrm{X}_{1}\right)$ meningkat 1 satuan persepsi maka penerimaan pajak badan (Y) naik sejumlah 0,150, dengan asumsi variabel lain diandaikan konstan.

$\beta_{2}=0,186$; bermakna bila variabel pemeriksaan pajak $\left(\mathrm{X}_{2}\right)$ bertambah 1 satuan persepsi sehingga penerimaan pajak badan (Y) naik sejumlah 0,186, berasumsi variabel lain diandaikan konstan.

$\beta_{3}=0,135$; bermakna bila variabel penagihan pajak $\left(\mathrm{X}_{3}\right)$ terjadi penambahan 1 satuan persepsi, maka akan terdapat penambahan penerimaan pajak badan (Y) sejumlah 0,135 , dengan asumsi variabel lain dianggap konstan.

$\beta_{4}=0,410$; bermakna bila variabel kesadaran wajib pajak $\left(\mathrm{X}_{4}\right)$ terjadi penambahan 1 satuan persepsi, maka akan terdapat penambahan penerimaan pajak badan (Y) 0,410, dengan asumsi variabel lain dianggap konstan.

Menurut hasil hitung regresi linear berganda ditemukan maka hasil uji menampilkan tingkat signifikansi sejumlah $0,039 \leq \alpha=0,05$. Hal tersebut dapat diartikan $\mathrm{H}_{0}$ ditolak dan $\mathrm{H}_{1}$ diterima. Dimaknai bermakna secara parsial, maka kewajiban kepemilikan NPWP memengaruhi pada penerimaan pajak, sehingga makin meningkat kewajiban kepemilikan NPWP di Kabupaten 
Gianyar maka penerimaan pajak akan makin bertambah. Hasil penelitian ini mendukung penelitian yang sebelumnya dilakukan (Sutrisno et al., 2016), (Saragih, 2017), yang memiliki hasil yaitu kewajiban kepemilikan NPWP memengaruhi penerimaan pajak dan bertolak atas penelitian oleh (Chatama, 2013) yamg menyatakan kewajiban kepemilikan NPWP tidak memiliki pengaruh parsial kepada penerimaan pajak

Menurut hasil hitung regresi linear berganda ditemukan maka hasil uji menampilkan tingkat signifikansi sejumlah $0,094 \leq \alpha=0,05$. Hal tersebut dapat diartikan $\mathrm{H}_{0}$ ditolak dan $\mathrm{H}_{1}$ diterima. Ini bermakna secara parsial pemeriksaan pajak memiliki pengaruh pada penerimaan pajak, yaitu semakin meningkat pemeriksaan pajak di Kabupaten Gianyar maka penerimaan pajak akan semakin bertambah. Hal ini mendukung penelitian sebelumnya oleh (Listyaningtyas, 2012), yang menemukan bahwa pemeriksaan pajak memengaruhi penerimaan pajak serta bertolak dengan penelitian oleh (Rahmawati et al., 2014) yamg menyatakan pemeriksaan pajak tidak memiliki pengaruh secara parsial kepada penerimaan pajak

Menurut hasil hitung regresi linear berganda ditemukan maka hasil uji menampilkan tingkat signifikansi sejumlah $0,046 \leq \alpha=0,05$. Hal tersebut dapat diartikan $\mathrm{H}_{0}$ ditolak dan $\mathrm{H}_{1}$ diterima. Ini bermakna secara parsial penagihan pajak memiliki pengaruh kepada penerimaan pajak, yaitu semakin meningkat penagihan pajak di Kabupaten Gianyar maka penerimaan pajak akan semakin bertambah. Hal ini mendukung penelitian sebelumnya oleh (Putra Mahendra \& Sukartha, 2014), (Adriana Erwis, 2012)), yang menemukan bahwa penagihan pajak memengaruhi penerimaan pajak dan bertolak dengan penelitian oleh (Fahrul,2016) yang menyatakan penagihan pajak tidak memiliki pengaruh secara parsial kepada penerimaan pajak 
Tjok Gde Agung Anggadhika W.P.P, dan I Ketut Jati. Pengaruh Kepemilikan NPWP...

Menurut hasil hitung regresi linear berganda ditemukan maka hasil uji menampilkan tingkat signifikansi sejumlah $0,000 \leq \alpha=0,05$. Hal tersebut dapat diartikan $\mathrm{H}_{0}$ ditolak dan $\mathrm{H}_{1}$ diterima. Ini bermakna secara parsial kesadaran wajib pajak memiliki pengaruh kepada penerimaan pajak, yaitu semakin meningkat kesadaran wajib pajak di Kabupaten Gianyar maka penerimaan pajak akan semakin bertambah. Hal ini mendukung penelitian sebelumnya oleh (Herryanto, 2013), (Hastuti, 2014), yang menemukan bahwa kesadaran wajib pajak memengaruhi penerimaan pajak dan bertolak dengan penelitian oleh (Darwin et al., 2014) yang pada variabel kesadaran wajib pajak, didapatkan tidak memiliki pengaruh secara parsial bagi penerimaan pajak Koefisien determinasi $\left(\mathrm{R}^{2}\right)$ mengukur berapa panjang kesanggupan model variabel independen untuk memberi arti tbagi variabel dependen. Di Hasil akhir SPSS, akan didapatkan koefisien determinasi yang terdapat di Model Summary ${ }^{b}$. Jika didapatkan nilai $\mathrm{R}^{2}=0$, hal tersebut diartikan tidak ada sedikit pun pengaruh yang diberikan oleh variabel independen terhadap variabel dependen. Jika didapatkan bila $\mathrm{R}^{2}=1$, hal tersebut diartikan pengaruh yang diberikan oleh variabel independen kepada terhadap dependen menjelaskan $100 \%$ variabel variasi variabel dependen

Tabel 6.

Hasil Uji Koefisien Determinasi $\left(\mathbf{U j i} \mathbf{R}^{2}\right)$

\begin{tabular}{ccccc}
\hline Model & $\mathrm{R}$ & $\mathrm{R}^{2}$ & $\mathrm{R}^{2}$ adjusted & $\begin{array}{c}\text { Standar } \\
\text { eror } \\
\text { estimasi }\end{array}$ \\
\hline 1 & $.790^{\mathrm{a}}$ & .624 & .608 & 1.707 \\
\hline
\end{tabular}

Sumber: Data diolah, 2018 
Hitung uji pada Tabel 6 menampilkan hasil dimana diperoleh jumlahnya nilai $\mathrm{R}^{2}$ adalah sebesar 0,624. Ini berarti variasi penerimaan pajak badan di KPP Pratama wilayah Gianyar dapat dijelaskan secara signifikan oleh variabel Kewajiban kepemilikan Nomor Pokok Wajib Pajak (NPWP) $\left(\mathrm{X}_{1}\right)$, Pemeriksaan pajak $\left(\mathrm{X}_{2}\right)$, Penagihan pajak $\left(\mathrm{X}_{3}\right)$, dan kesadaran wajib pajak (WP) $\left(\mathrm{X}_{4}\right)$ sebesar 62,4 persen, 37,6 persen sisanya diberitahu faktor lain diluar penelitian ini.

Uji Statistik t dipergunakan menguji pengaruh variabel independen pada variabel dependennya. Jika nilai signifikansinya $<0,05$, dapat diartikan hipotesis alternatif diterima. Jika nilai $>0,05$, dapat diartikan hipotesis alternatif ditolak, seperti terlihat pada tabel berikut

Tabel 7.

Hasil Uji Pada Kelayakan Model

\begin{tabular}{crrrrrr}
\hline Model & Sum of Squares & df & Mean Square & \multicolumn{2}{c}{ FSig. } \\
\hline Regression & & & & & & \\
1Residual & 459.511 & 4 & 214.878 & 39.420 & $.000^{\mathrm{b}}$ \\
\hline Total & 276.849 & 95 & 2.914 & & \\
\hline
\end{tabular}

Sumber: Data diolah, 2018

Pada tabel terlihat tingkat signifikan sebesar $0.000<0,05$. Hal tersebut dapat diartikan variabel independen yang diuji antara lain Variabel Kewajiban Kepemilikan Nomor Pokok Wajib pajak (NPWP), Pemeriksaan Pajak, Penagihan Pajak, Kesadaran Wajib Pajak (WP) berpengaruh signifikan secara simultan.

\section{SIMPULAN}

Kewajiban kepemilikan NPWP, Pemeriksaan pajak, Penagihan pajak, dan Kesadaran wajib pajak memengaruhi penerimaan pajak badan secara potifi. Semakin bertambahnya kepemilikan NPWP oleh WP, maka makin bertambah penerimaan pajak. 
Tjok Gde Agung Anggadhika W.P.P, dan I Ketut Jati. Pengaruh Kepemilikan NPWP...

Bagi wajib pajak disarankan bagi yang yang belum memiliki NPWP agar segera mengurus NPWP di KPP. Dan selalu melaksanakan kewajiban perpajakannya bahkan setelah dilakukan pemeriksaan dan penagihan. Kesadaran wajib pajak ini diperlukan agar penerimaan pajak dapat meningkat sehingga dapat dipakai untuk kepentingan masyarakat guna meningkatkan kesejahteraan masyarakat dan pembiayaan pembangunan. DJP sebagai badan yang bertugas melakukan tugas perpajakan dimana KPP Pratama Gianyar yang telah melakukan kewajiban dengan baik agar semakin meningkatkan kepemilikan NPWP dengan melakukan penyuluhan penyuluhan ke WP yang belum ber-NPWP serta penyuluhan untuk meningkatkan kesadaran wajib pajak. Sehingga mampu menambah penerimaan pajak khususnya di KPP Pratama Gianyar, Disarankan untuk peneliti selanjutnya mencantumkan ada/tidaknya kepemilikan NPWP oleh responden, Bagi KPP berdasarkan jawaban dari hasil kuisioner didapatkan beberapa saran yaitu perlunya kepemilikan NPWP dievaluasi untuk kemudahan wajib pajak melaksanakan administrasi perpajakan, mengedukasi petugas agar menunjukan identitas dan surat perintah pemeriksaan saat melakukan pemeriksaan kepada WP, memberikan sosialisasi kepada wajib pajak tentang pentingnya KPP tegas dalam menerapkan penagihan pajak sesuai dengan amanat undang-undang dan memberikan sosialisasi kepada wajib pajak tentang pentingnya pajak sebagai kewajiban warga negara dan pajak sebagai penerimaan negara

\section{REFERENSI}

Adriana Erwis, N. (2012). Efektivitas Penagihan Pajak Dengan Surat Teguran Dan Surat Paksa Terhadap Penerimaan Pajak Pada Kantor Pelayanan Pajak Pratama Makassar Selatan.

Ahmed, N., Chetty, R., Mobarak, M., Rahman, A., \& Singhal, M. (2012). Improving Tax Compliance On Developing Economies. 
Chatama, Y. J. (2013). The impact of ICT on Taxation : the case of large taxpayer department of tanzania revenue authority.

Coleman, S. (1996). The minnesota income tax compliance experiment state tax result.

D., J. A., Graetz, M. J., \& Wilde, L. L. (1990). The Effect Of Audit Rates On Federal Invidual Income Tax.

Daniel Mirera, N. (2014). The Effect Of Tax Audit On Revenue Collection: Case Of Kenya Revenue Authority.

Darwin, A., Darwin, A., \& Putri, D. (2014). Kesadaran Wajib Pajak dan Pelayanan Pajak terhadap Kinerja Penerimaan Pajak di Kota Padang.

Diana, A., \& Setiawati, L. (2009). Perpajakan Indonesia.

Doherty, J. (2014). Increasing Tax Revenue And Its Impact On Financing Public Healthcare In South Africa.

Drogalas, G., Ioannis, S., \& Dimitra, Karagiorgou Ioannis, D. (2015). Tax audit effectiveness in Greek firms: Tax auditors' perceptions.

Fahrul, A. (2016). Pengaruh Pemeriksaan Dan Penagihan Pajak Terhadap Penerimaan Pajak Pada Kantor Pelayanan Pajak Pratama Makassar Utara.

Febriyanti, I. (2013). Pengaruh Kewajiban Kepemilikan Nomor Pokok Wajib pajak (NPWP), Pemeriksaan Pajak, Dan Penagihan Pajak Terhadap Penerimaan Pajak (Pada KPP Pratama Di Wilayah Jakarta Selatan).

Fitrianingsing, M. (2017). Pengaruh Pemeriksaan Pajak Dan Penagihan Pajak Terhadap Penerimaan Pajak Pada Kantor Pelayanan Pajak Pratama Makassar Selatan. 
Tjok Gde Agung Anggadhika W.P.P, dan I Ketut Jati. Pengaruh Kepemilikan NPWP...

Ginting, R. (2006). Pengaruh Pemberian Surat Penagihan terhadap Pembayaran Tunggakan Pajak Penghasilan. Jurnal Ekonomi \& Bisnis, Vol.5, No.1.

Giroth, D., Saerang, D. P. ., \& Jessy J.E., W. (2016). Analisis Efektivitasvpemeriksaan Pajak Dalam Upaya Meningkatkan Penerimaan Pajak Pada Kantor Pelayanan Pajak Pratama Manado. Hastuti, R. (2014). Tax Awareness And Tax Education : A Perception Of Potential Taxpayer. Herryanto, M. (2013). Pengaruh Kesadaran Wajib Pajak, Kegiatan Sosialisasi Perpajakan, dan Pemeriksaan Pajak terhadap Penerimaan Pajak Penghasilan di KPP Pratama Surabaya Sawahan. Hutagaol, J., Winarto, W. W., \& Pradipta, A. (2007). Strategi Meningkatkan Kepatuhan Wajib Pajak. Dalam Akuntabilitas. Vol 6(2).

Indriantoro, N., \& Bambang Supomo. (2004). Metodologi Penelitian bisnis Untuk Akuntansi dan Manajemen.

Junaidy, S., \& Sandra, A. (2009). Evaluasi Proses Pada Pelaksanaan Penagihan Pajak Dalam Rangka Pengamanan Penerimaan Pajak.

Ladi, O. M., \& Iwarere T, H. (2015). Effect Of Tax Audit On Revenue Generation : Federal Inland Revenue Service, Abuja Experience.

Listyaningtyas, E. F. (2012). Efektivitas Pelaksanaan Pemeriksaan Dalam Rangka Meningkatkan Penerimaan Negara dari Sektor Pajak (Studi kasus di KPP Tulungagung.

Manik, A. W. (2009). Pengaruh Kualitas Pelayanan, Biaya Kepatuhan Pajak, dan Kesadaran Wajib Pajak pada Kepatuhan Pelaporan Wajib Pajak Badan yang Terdaftar di Kantor Pelayanan Pajak Madya Denpasar.

Mardiasmo. (2011). Perpajakan, Edisi Revisi.

Moh, Z. (2004). Manajemen Perpajakan. 
Nurmantu, S. (2003). Pengantar Perpajakan.

Pardiat. (2008). Pemeriksaan Pajak Ed. 2.

Putra Mahendra, P., \& Sukartha, I. M. (2014). Pengaruh Kepatuhan, Pemeriksaan Dan Penagihan Pajak Pada Penerimaan Pajak Penghasilan Badan.

Putriani, I. A. N., \& Budiartha, I. ketut. (2016). Pengaruh penyuluhan perpajakan dan pelayaran fiskus pada penerimaan pajak penghasilan badan.

Rahayu, S. K. (2014). Pengaruh Pemeriksaan Pajak dan Kepatuhan Wajib Pajak terhadap Penerimaan Pajak Penghasilan Wajib Pajak Badan di Kantor Pelayanan Pajak Pratama Surakarta.

Rahmawati, F. N., Santoso, S., \& Hamidi, N. (2014). PENGARUH PEMERIKSAAN DAN KEPATUHAN WAJIB PAJAK TERHADAP PENERIMAAN PAJAK PENGHASILAN BADAN DI SURAKARTA. Jupe UNS, Vol 3, No 1, Hal 72 s/d 82.

Samuel, M., \& Jean D.D., R. (2014). The Impact Of Taxpayer Financial Statement Audit On Tax Revenue Growth.

Saragih, W. (2017). Pengaruh Kepemilikan NPWP Dan Pemeriksaan Pajak Terhadap Penerimaan Pajak (studi Kasus Pada Kantor Pelayanan Pajak Prata Majalaya Periode 20112015).

Sari, M. M. R., \& Afriyanti, N. N. (2012). pengaruh kepatuhan wajib pajak dan pemeriksaan pajak terhadap penerimaan pph pasal 25/29 wajib pajak badan pada kpp pratama denpasar timur. Sugiyono. (2009). Metode Penelitian Bisnis Cetakan 13. 
Tjok Gde Agung Anggadhika W.P.P, dan I Ketut Jati. Pengaruh Kepemilikan NPWP...

Sutrisno, B., Arifati, R., \& Andini, R. (2016). Pengaruh Kewajiban Kepemilikan NPWP, Pemeriksaan Pajak, Penagihan Pajak, Surat Paksa Pajak, dan Kesadaran Wajib Pajak Terhadap Penerimaan Pajak.

Syahab, Z., \& A, G. H. (2008). Pengaruh Penagihan Pajak dan Surat Paksa Pajak Terhadap Penerimaan Pajak Penghasilan Badan. Jurnal Ekonomi Bisniss Vol.13(2).

Undang-Undang Nomor 28 Tahun 2007 tentang Ketentuan Umum dan Tata Cara Perpajakan. Tansuria, B. I. (n.d.). Pokok-pokok Ketentuan Umum Perpajakan (KUP)”, Cetakan Pertama. Trisnayanti, I. A. I., \& Jati, I. K. (2915). Pengaruh Self Assessment System, Pemeriksaan Pajak, dan Penagihan Pajak pada Penerimaan Pajak Pertambahan Nilai (PPN).

Vegirawati, T. (2011). Hubungan Antara Penerbitan Surat Tagihan Pajak Dengan Penerimaan Pajak Pada KPP Pratama Ilir Timur Palembang”, Palembang.

Wahyudin, R. K. (2014). Pengaruh Efektivitas Administrasi Perpajakan Dan Pemeriksaan Pajak Terhadap Penerimaan Pajak (Survey Pada 6 KPP Pratama Kanwil Jawa Barat I). 